\title{
Comparison of mitochondrial genome and development of specific PCR primers for identifying two scuticociliates, Pseudocohnilembus persalinus and Uronema marinum
}

Yu-Xi Huang ${ }^{1}$, Sen Wang ${ }^{1}$, Yan-Qi Gao' ${ }^{1}$ Jie-Hu Chen², Xiu-Li Wang ${ }^{1}$ and Rui-Jun Li*

\begin{abstract}
Background: Pseudocohnilembus persalinus and Uronema marinum (Ciliophora, Scuticociliatia), as parasitic scuticociliatid ciliates, were isolated from Scophthalmus maximus and Takifugu rubripes, respectively, in our previous studies. These ciliates are morphologically very similar; hence, it is difficult to identify specific scuticociliate species using traditional classification methods for performing taxonomic research and disease control studies.

Methods: We annotated the mitochondrial genomes of these two scuticociliates on the basis of previous sequencing, including analyses of nucleotide composition, codon usage, $\mathrm{Ka} / \mathrm{Ks}$, and $\mathrm{p}$-distance. We also compared the nucleotide and amino acid similarity of the mitochondrial genomes of P. persalinus, U. marinum, and other 12 related ciliates, and a phylogenetic tree was constructed using 16 common genes. We chose the nad 4 and nad7 genes to design specific PCR primers for identification.

Results: P. persalinus and U. marinum were found to have a close evolutionary relationship. Although codon preferences were similar, differences were observed in the usage of codons such as CGA, CGC, and GTC. Both $\mathrm{Ka} / \mathrm{Ks}$ and p-distance were less than 1. Except for yejR, ymf57, ymf67, and ymf75, the amino acid sequence similarity between $P$. persalinus and U. marinum was greater than $50 \%$.

Conclusions: The mitochondrial genomes of P. persalinus and U. marinum were thoroughly compared to provide a reference for disease prevention and control. The specific PCR primers enabled us to identify P. persalinus and U. marinum rapidly and accurately at the molecular level, thus providing a basis for classification and identification.
\end{abstract}

Keywords: Pseudocohnilembus persalinus, Uronema marinum, Genome comparison, Specific PCR primers

*Correspondence: liruijun@dlou.edu.cn

${ }^{1}$ Liaoning Key Laboratory of Marine Animal Immunology, Dalian Key Laboratory of Marine Animal Disease Control and Prevention, College of Fisheries and Life Science, Dalian Ocean University, Dalian, Liaoning 116023, People's Republic of China

Full list of author information is available at the end of the article

\section{Background}

In recent years, there has been an increase in the occurrence and extent of damage due to diseases of mariculture animals caused by ciliates. Scuticociliatosis, a disease caused by a type of ciliates known as scuticociliates, occurs globally and has led to a high fatality rate of fishes $[1,2]$. Scuticociliates include approximately 20 species that cause scuticociliatosis, including Miamiensis

c) The Author(s) 2021. This article is licensed under a Creative Commons Attribution 4.0 International License, which permits use, sharing, adaptation, distribution and reproduction in any medium or format, as long as you give appropriate credit to the original author(s) and the source, provide a link to the Creative Commons licence, and indicate if changes were made. The images or other third party material in this article are included in the article's Creative Commons licence, unless indicated otherwise in a credit line to the material. If material is not included in the article's Creative Commons licence and your intended use is not permitted by statutory regulation or exceeds the permitted use, you will need to obtain permission directly from the copyright holder. To view a copy of this licence, visit http://creativeco mmons.org/licenses/by/4.0/. The Creative Commons Public Domain Dedication waiver (http://creativecommons.org/publicdomain/ zero/1.0/) applies to the data made available in this article, unless otherwise stated in a credit line to the data. 
avidus, Uronema marinum, Uronema nigricans, Metanophrys orientalis, Pseudocohnilembus persalinus, and Pseudocohnilembus hargisi [3-7]. The species of parasitic scuticociliates differ according to the different living environments of the host, but the symptoms caused by them are very similar [8]. Scuticociliates can not only invade the body surface, skin, fin, and muscle of fishes but also their abdominal cavity, kidney, pancreas, and even brain. Scuticociliates cause blackening of fish body color, tissue and organ bleeding, ulceration, and other pathological changes, leading to the death of Paralichthys olivaceus, Thunnus maccoyii, Scophthalmus maximus, and Dicentrachus labrax [4, 9-12]. Thus, to prevent and control scuticociliatosis effectively and rapidly, it is important to accurately detect scuticociliates. However, the morphological forms of the subclass Scuticociliatia are very similar. The body of scuticociliates is $20-45 \mu \mathrm{m}$ long, melon seed-shaped, and covered with cilia. Therefore, it is difficult to distinguish scuticociliates using a light microscope. Previously, the species of scuticociliates could only be identified through repeated verification by a series of methods such as scanning electron microscopy, protein silver staining, and silver impregnation. Although the morphological analysis of scuticociliates is a useful approach to identify them, it is time-consuming and laborious, and is thus not suitable for wider use practically in treating scuticociliatosis. Moreover, morphological analysis is based on staining techniques, which may obscure subtle changes, leading to identification errors [13]. The ribosomal small subunit rDNA (SSU-rDNA) sequence analysis method is a universal tool for parasite classification. However, the SSU-rDNAs of related parasite species show few differences, which limits the identification of closely related species [14].

In a preliminary study, we isolated $P$. persalinus and $U$. marinum from Scophthalmus maximus and Takifugu rubripes, respectively $[15,16]$. P. persalinus and $U$. marinum are dominant scuticociliate pathogens that are distributed in the north of China marine aquaculture area [17]. In our previous studies, we sequenced the whole mitochondrial genomes of $P$. persalinus and $U$. marinum $[15,16]$. In the present study, we analyzed interspecific differences in the mitochondrial genome between $P$. persalinus and $U$. marinum by comparing codon usage, Ka/ $\mathrm{Ks}$, and $\mathrm{p}$-distance. We also revealed evolutionary relationships and mitochondrial genome differences between these species and 12 related ciliates by constructing a phylogenetic tree and comparing nucleotide and amino acid similarity of the mitochondrial genomes. Specific PCR primers for identification were designed according to the specific genes in the mitochondrial genomes of $P$. persalinus and $U$. marinum. These primers enable easy, rapid, and accurate species identification at the molecular level. The use of PCR primers to identify scuticociliates provided the basis for the classification and identification of scuticociliates.

\section{Methods \\ Whole mitochondrial genomes of $P$. persalinus and $U$. marinum}

The whole mitochondrial genome sequences of $P$. persalinus and $U$. marinum were deposited in NCBI (https:// www.ncbi.nlm.nih.gov/) with accession numbers MH608212 and MG272262, respectively.

\section{Annotation of the mitochondrial genome}

The MITOS (http://mitos.bioinf.uni-leipzig.de/index. py) [18] and ORF Finder (https://www.ncbi.nlm.nih. gov/orffinder/) tools were used to preliminarily annotate mitochondrial genome sequences. BLASTp and BLAST (https://blast.ncbi.nlm.nih.gov/Blast.cgi) were used to compare the preliminary results of annotation with encoded protein and rRNA sequences belonging to the reported related species in order to verify the accuracy of the results and make corrections. The schematic diagram was drawn using OGDRAW (https://chlorobox.mpimpgolm.mpg.de/OGDraw.html).

\section{Analysis of codon usage}

The codon usage bias of $P$. persalinus and $U$. marinum was compared. The RSCU was calculated using the formula described in the study by Sharp and Li [19].

\section{Analysis of $\mathrm{Ka} / \mathrm{Ks}$ and $\mathrm{p}$-distance}

$\mathrm{Ka} / \mathrm{Ks}$ analysis was performed on 25 common encoding genes of $P$. persalinus and $U$. marinum. MUSCLE v3.8.31 (http://www.drive5.com/muscle/) software was used to compare the selected 25 common encoding genes of $P$. persalinus and $U$. marinum [20]. The KaKs_Calculator 2.0 was then used to calculate the $\mathrm{Ka} / \mathrm{Ks}$ of all compared sequences [21], and MEGA6 software was used to calculate p-distance [22].

\section{Phylogenetic analysis}

The complete mitochondrial sequences of 12 ciliates related to $P$. persalinus and $U$. marinum were downloaded from NCBI for phylogenetic tree construction. The sequences used for comparison and their GenBank accession numbers were as follows: Tetrahymena paravorax (Accession Number: NC_008338.1), Tetrahymena pyriformis (Accession Number: NC_000862.1), Tetrahymena thermophila (Accession Number: NC_003029.1), Paramecium caudatum (Accession Number: NC_014262.1), Tetrahymena pigmentosa (Accession Number: NC_008339.1), Tetrahymena malaccensis (Accession Number: NC_008337.1), Laurentiella strenua 
(Accession Number: KX529838.1), Thuricola similis (Accession Number: MW221262), Oxytricha trifallax (Accession Number: JN383843), Halteria grandinella (Accession Number: MT471317), Euplotes vanleeuwenhoeki (Accession Number: MK889230), and Urostyla grandis (Accession Number: KX494929.1). Sixteen common encoding genes of the complete mitochondrial genome of all ciliates were selected for phylogenetic tree construction. MUSCLE v3.8.31 software (http:// www.drive $5 . \mathrm{com} / \mathrm{muscle} /$ ) was used to compare individual genes among all 14 ciliates. The jModelTest 2.1.7 (https://code.google.com/p/jmodeltest2/) [23] was used for testing the nucleic acid model, and the model with the minimum Akaike information criterion (AIC) value was selected as the best model for phylogenetic tree construction. MrBayes v3.2.6 (http://nbisweden.github.io/MrBay es/manual.html) was used to construct phylogenetic trees with Bayesian inference [24], and RAxML 8.1.5 (https://sco.h-its.org/exelixis/web/software/raxml/index. html) was used to construct a phylogenetic tree using the maximum likelihood (ML) method, with the bootstrap value set to 1000 [25].

\section{Comparison of nucleotide and amino acid similarity of mitochondrial genomes of 14 related ciliates}

The COGs and identity comparison of the whole mitochondrial genomes belonging to $P$. persalinus, $U$. marinum, and 12 other related ciliates were analyzed [26]. According to the species arrangement and common gene information of the phylogenetic tree, genoPlotR (http:// genoplotr.r-forge.r-project.org/) [27] was used to compare and analyze the common genes of these 14 species.

\section{Design of specific PCR primers for identification}

The whole mitochondrial genome sequences of $P$. persalinus and $U$. marinum were compared. Next, genes with both intraspecific relative conservatism and interspecific diversity among scuticociliates were selected. Among the selected genes, we chose nad4 and nad7. Primer Premier 5 was used to design specific primers based on nad4 and nad7. Primers P2-F (5'-GTTATGGTTACAATGTTT GGTGTTAT-3) and P2-R (5'-TATAGTACCAACATG TTTTCTCATCA-3) were designed based on the nad4 sequence of $P$. persalinus; primers P3-F (5'-ATTGTTCTA TGCTTATGCAA-3) and P3-R (5'-TGTTTAGTAGAA CTATTATTCAT-3) were designed based on the nad7 sequence of $U$. marinum. The PCR reaction system consisted of a $40 \mu \mathrm{L}$ reaction mixture containing $20 \mu \mathrm{L} \mathrm{KOD}$ buffer, $0.8 \mu \mathrm{L}$ KOD enzyme (KOD FX, Toyobo Biotech Co., Shanghai), $8 \mu \mathrm{L} 2 \mathrm{mM}$ dNTPs, $2 \mu \mathrm{L}$ forward primer, $2 \mu \mathrm{L}$ reverse primer, $2 \mu \mathrm{L}$ model DNA, and $5.2 \mu \mathrm{L}$ sterile purified water. The PCR reaction conditions were as follows: $94{ }^{\circ} \mathrm{C}$ for $3 \mathrm{~min}, 98{ }^{\circ} \mathrm{C}$ for $15 \mathrm{~s}, 56{ }^{\circ} \mathrm{C}$ for $30 \mathrm{~s}$, $68{ }^{\circ} \mathrm{C}$ for $45 \mathrm{~s}$, followed by 35 cycles and $68^{\circ} \mathrm{C}$ for $5 \mathrm{~min}$. Finally, the results were confirmed by agarose gel electrophoresis. The PCR products were sent to Sangon Biotech Co. (Shanghai, China) for nucleic acid sequencing, and the obtained sequences were compared with the target sequences.

\section{Results \\ Comparison of mitochondrial genomes of $P$. persalinus and U. marinum}

According to the data given in Table 1, the entire mitochondrial genome of $U$. marinum was $1470 \mathrm{bp}$ longer than that of $P$. persalinus. The protein-coding gene region of $U$. marinum was $755 \mathrm{bp}$ longer than that of $P$. persalinus and contained three more genes than that of P. persalinus. Although both $P$. persalinus and $U$. marinum have a strong AT preference, the AT preference of $U$. marinum was stronger than that of $P$. persalinus. The AT percent in the entire mitochondrial genome of $P$. persalinus was $77.04 \%$, and that of $U$. marinum was $80.99 \%$. The AT (all) of $U$. marinum was $4.44 \%$ greater than that of $P$. persalinus, and the AT (third) of $U$. marinum was $9.8 \%$ greater than that of $P$. persalinus. Figure 1 shows apparent differences between the mitochondrial genomes of $P$. persali$n u s$ and $U$. marinum. The order and distribution of heavy and light chains of all common amino acid coding genes were consistent. In $U$. marinum, ymf57, orf346, orf141,

Table 1 Comparison of mitochondrial genomes of P. persalinus and U. marinum

\begin{tabular}{|c|c|c|c|c|c|c|c|c|c|c|c|}
\hline \multirow[t]{2}{*}{ Species } & \multirow[t]{2}{*}{ Length (bp) } & \multicolumn{7}{|c|}{ Entire genome } & \multicolumn{3}{|c|}{ Protein-coding gene } \\
\hline & & $A(b p)$ & $\mathrm{T}(\mathrm{bp})$ & $C(b p)$ & $G(b p)$ & $N(b p)^{a}$ & Genes & GC (\%) & Length (aa) & AT (\%) (all) & AT (\%) (3rd) \\
\hline Pseudocohnilembus persalinus & 38,375 & 14430 & 15135 & 4101 & 4509 & 200 & 40 & 22.44 & 9174 & 77.01 & 76.18 \\
\hline Uronema marinum & 39,845 & 15869 & 16404 & 4562 & 4010 & 0 & 43 & 19 & 9929 & 81.45 & 85.98 \\
\hline
\end{tabular}

${ }^{a}$ The mitochondrial genome of $P$. persalinus had two gaps, and the length of gaps was unknown. The number of N in each gap region was in accordance with NCBI sequence submission requirements, and the default was 100

Length (aa): Total length of amino acid sequence of all mitochondrial proteins. "aa" represents amino acids; AT (\%) (all): The percentage of the A and T base of the coding region sequence of all proteins in the total coding region sequence; AT (\%) ( $3 \mathrm{rd}$ ): The percentage of the sequence consisting of the sum of $A$ and T bases in the third base of all amino acid codons 


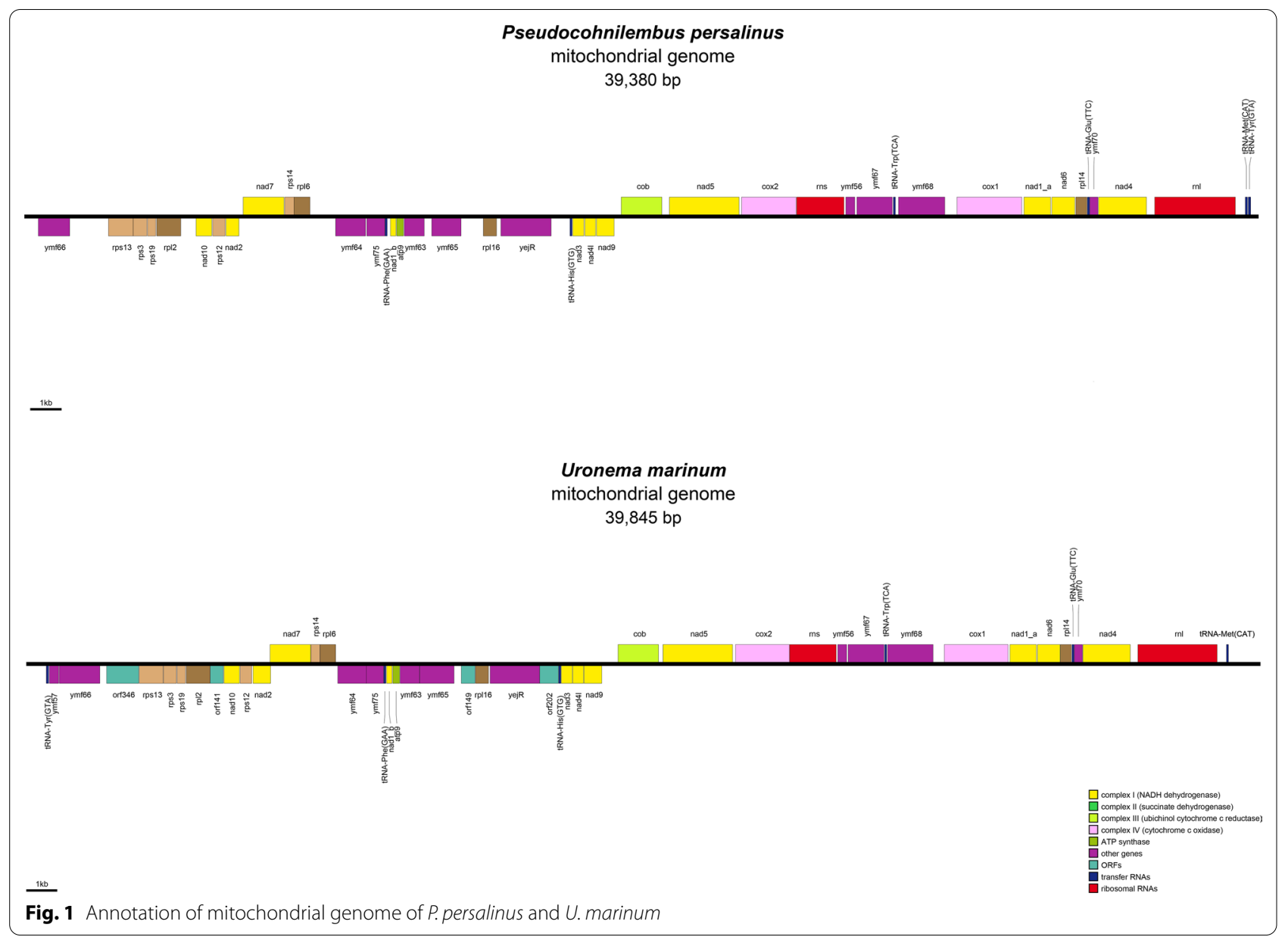

orf149, and orf202 were annotated, and the gap between rpl6 and $y m f 64, y m f 63$ and $y m f 65$, and nad 9 and cob was larger.

\section{Analysis of codon usage}

Figure 2 shows that in general, the whole mitochondrial genome of $P$. persalinus and $U$. marinum had almost the same preference for relative synonymous codons, with only a slight difference. The usage of CAG that coded for Gln and AAG that coded for Lys in P. persalinus was higher (0.286 and 0.353, respectively) than that in $U$. marinum. In P. persalinus, CGA and CGC coded for Arg and GTC coded for Val. The usage degrees were 0.020, 0.061 , and 0.140 , respectively. However, in $U$. marinum, CGA and CGC were not used to code for Arg; in contrast, the usage of AGA for coding Arg was 0.353 higher than that for P. persalinus; moreover, GTC was not used in $U$. marinum to code for Val.

\section{Analysis of $\mathrm{Ka} / \mathrm{Ks}$ and $\mathrm{p}$-distance}

The Ka/Ks values (Fig. 3) of 25 common encoding genes of $P$. persalinus and $U$. marinum were less than one, which indicated that the encoding genes were mainly subjected to negative selection and the overall gene evolution tended to be conservative. Among the 25 common encoding genes, $\mathrm{Ka} / \mathrm{Ks}$ of $y e j R$ was relatively high at 0.59 , which suggested that it may have a relatively relaxed selection pressure. The specific value of $\mathrm{Ka} / \mathrm{Ks}$ is shown in Additional file 1: Table S1.

The data provided in Fig. 4 showed that the 3rd p-distance, except for nad1-a, nad9, rpl16, rpl2, and rpl6, was higher than the p-distance obtained by the other two calculation methods, and the largest difference was observed for nad10. The codons of the $\operatorname{cox} 2$, nad1-a, nad9, rpl6, and rps19 genes did not show much difference in the p-distance calculated from the first and second bases or the third base and the CDS region, probably because Met or proteins with strong codon preference accounted for a large proportion of the proteins encoded by them.

\section{Phylogenetic tree}

The clustering results showed that $P$. persalinus and $U$. marinum were clustered together. P. persalinus and 

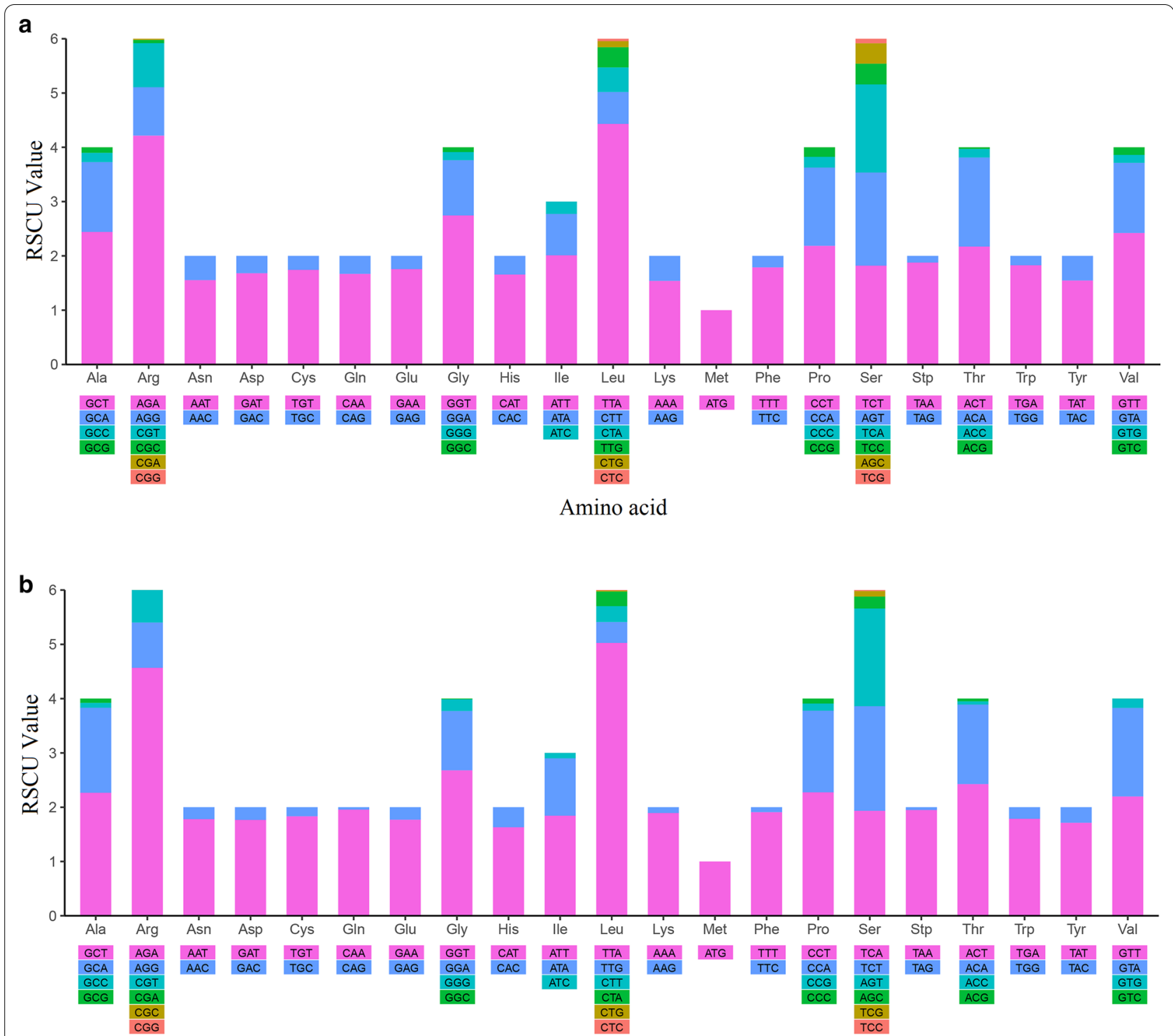

Amino acid

Fig. 2 Relative synonymous codon usage of the mitochondrial genome of P. persalinus and U. marinum. a P. persalinus. b U. marinum

U. marinum belonged to Philasterida and were closely related to Paramecium caudatum which belonged to Peniculida. Other ciliates were in obvious clades: Hymenostomatida, Peniculida, Sessilida, Sporadotrichida, Urostylida, and Euplotida (Fig. 5).

\section{Comparison of nucleotide and amino acid similarity of the mitochondrial genomes of 14 related ciliates}

The results showed that most of the functional genes annotated by COGs were related to secondary metabolite biosynthesis, transport, and catabolism. This indicates that these functions were essential for the growth and reproduction of ciliates and that these genes were also the most conservative ones. Except for $y e j R, y m f 57$, $y m f 67$, and $y m f 75$, the amino acid sequence identity of other genes of both $P$. persalinus and $U$. marinum was greater than $50 \%$. The amino acid sequence of the nad 10 gene was the most identical among the compared species; the identity of nad10 was $>80 \%$ in six ciliates and $>60 \%$ in all ciliates. Additionally, the $\operatorname{rps} 12$, nad7, nad1-b, atp9, nad3, cob, cox1, nad1-a, and nad4 genes were also highly identical. The identity of the nad 3 and nad4 genes in seven ciliates; the nad1-b, atp9, cob, cox1, and nad1$a$ genes in eight ciliates; the rps 12 gene in nine ciliates; and the $n a d 7$ gene in 12 ciliates was $>50 \%$, which indicated that they were relatively conserved genes among 


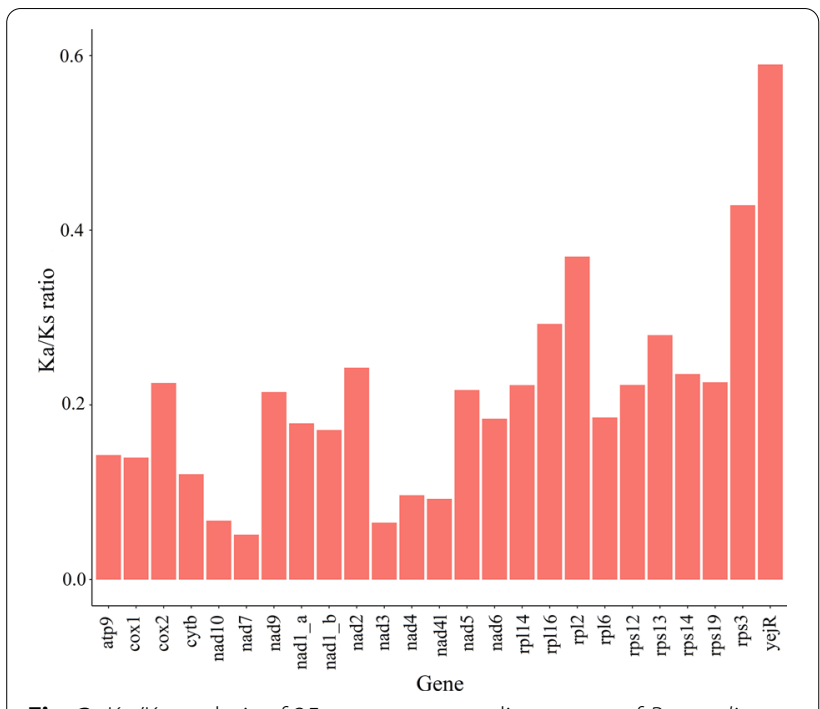

Fig. $3 \mathrm{Ka} / \mathrm{Ks}$ analysis of 25 common encoding genes of $P$. persalinus and U. marinum

these species. The identity of nad7 was $<50 \%$ only in $L$. strenua. The nad7 gene plays a role in the biosynthesis, transport, and catabolism of secondary metabolites as well as in energy production and conversion. Perhaps $L$. strenua is very different from other ciliates with regard to some of these aspects. The $y m f 66$, rps 13, rps19, rpl2, rps14, rpl6, ymf64, ymf63, ymf65, rpl16, and ymf56 genes had a high identity of greater than $50 \%$ in $P$. persalinus and $U$. marinum, but less than $50 \%$ identity in other ciliates. This is probably because $P$. persalinus and $U$. marinum are phylogenetically close species which are isolated from other ciliates.

In addition, the identity of several nucleotide sequences such as tRNA-Tyr (GTA), nad10, rps12, nad7, tRNAPhe (GAA), nad1-b, atp9, nad3, cob, rns, tRNA-Trp (TCA), cox1, nad1-a, nad4, and $r n l$ was relatively high. This result is consistent with the identity of amino acid sequences. Among them, $r n s$ and $r n l$ encoded rRNA; tRNA-Tyr (GTA), tRNA-Phe (GAA), and tRNA-Trp (TCA) encoded tRNA; nad10, nad7, nad1-b, atp9, nad3, cob, cox1, nad1- $a$, and nad4 were related to the biosynthesis of secondary metabolites, transport, and catabolism as well as to energy production and conversion; and rps12 was related to chromatin structure and dynamics as well as to the biosynthesis of secondary metabolites, transport, and catabolism. This finding showed that all 14 ciliates had similar secondary metabolite transport and metabolic patterns.

Combined with the analysis of the phylogenetic tree (Fig. 5), it was found that the length and arrangement of the common 16 genes of these ciliates are very different at the order level (Fig. 6). Considering the order Philasterida to which $P$. persalinus and $U$. marinum belong as a benchmark, in the order Hymenostomatida, which is most closely related to Philasterida, the common genes are not different in the order in which they are arranged, with only slight differences in the length

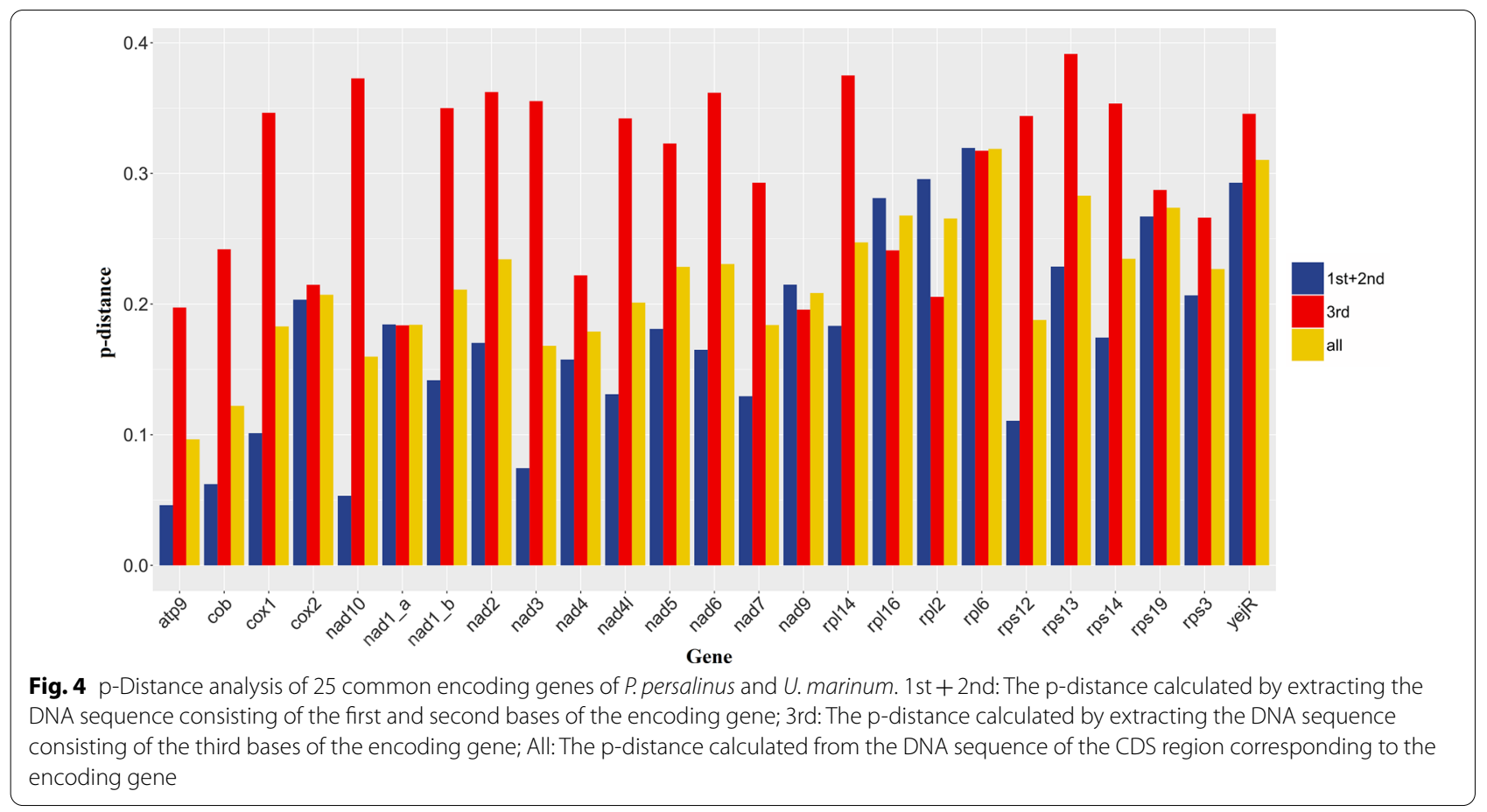




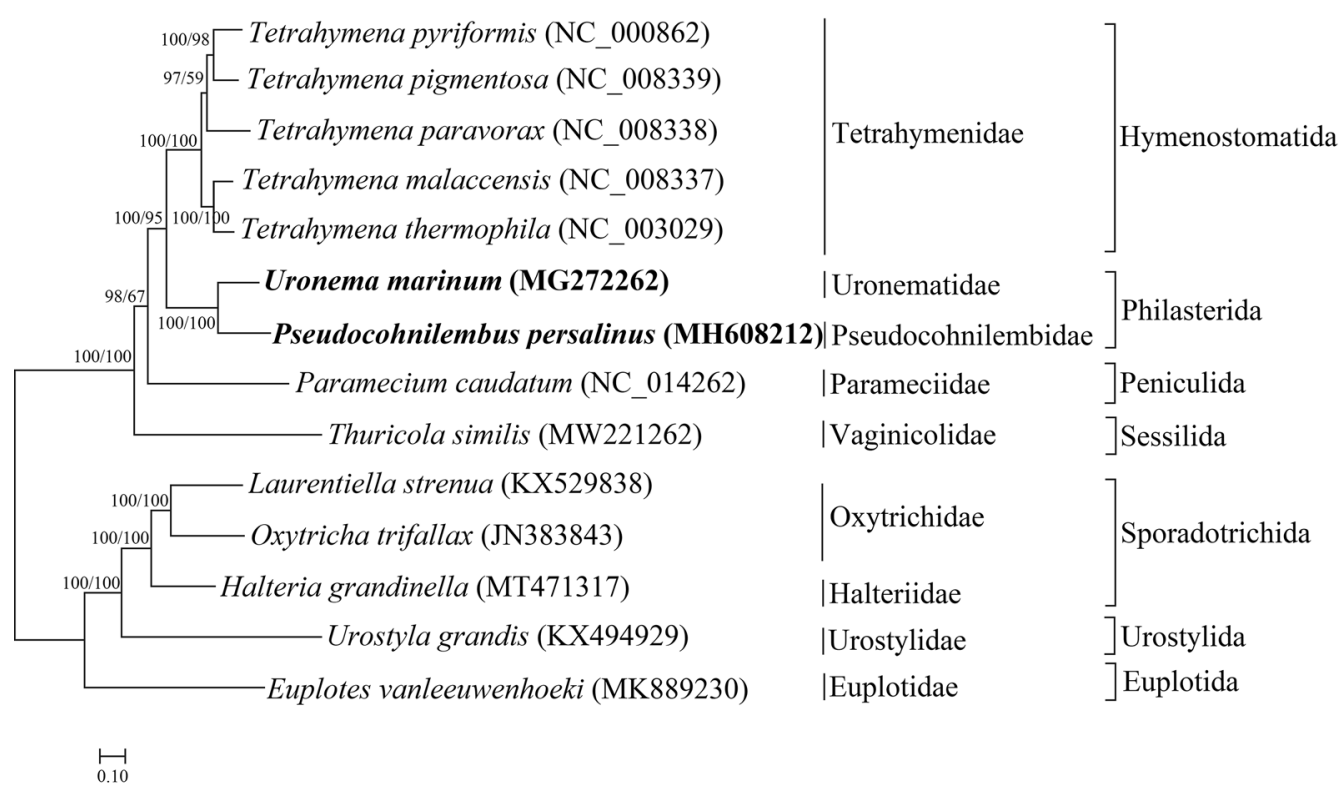

Fig. 5 Phylogenetic tree. The length of the branches indicates the genetic distance between the ciliates. About the bootstrap value, the first value is the result of the $\mathrm{Bl}$ algorithm, and the latter is the result of the $\mathrm{ML}$ algorithm

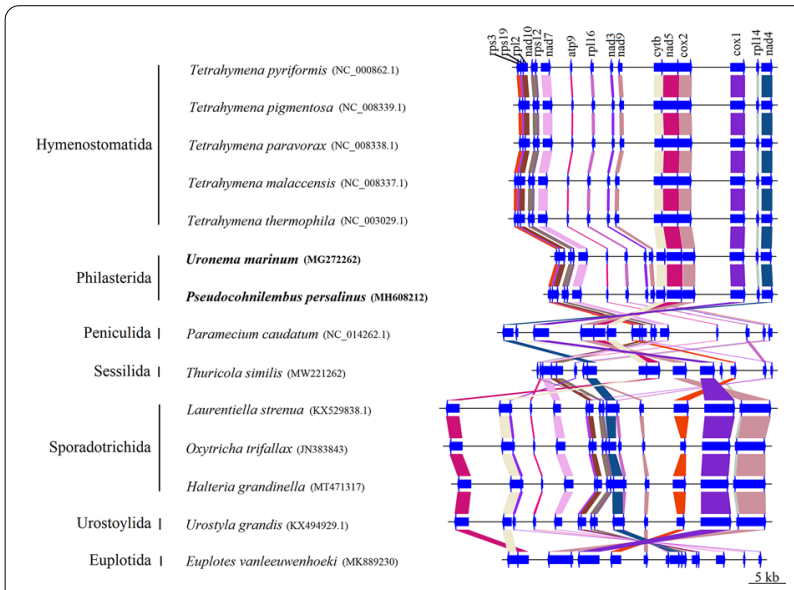

Fig. 6 Comparison and analysis of the common genes of 14 ciliates. An arrow to the right indicates that the gene is present on the heavy chain, and an arrow to the left indicates that the gene is present on the light chain

and distribution of light and heavy chains. A large number of rearrangements occurred in other orders of ciliates, wherein the length and distribution of light and heavy chains are also very different. Moreover, Sporadotrichida and Urostylida have the same sort order of common genes, wherein rps12 is slightly distant from nad4 in Urostylida. In all 14 ciliates, rps19 and $r p l 2$, and nad10 and rps12 are always next to each other.

\section{Specific primer design and amplification}

The result of comparison of the selected gene sequences and design of primers is shown in Fig. 7. The amplification results of specific primers (Fig. 8) indicated that the designed specific primers had good specificity. When the P2 primer was used to amplify the DNA of $P$. persalinus and $U$. marinum, only the lanes using the $P$. persalinus gene as a template showed a single clear band. When the P3 primer was used to amplify the DNA of $P$. persalinus and $U$. marinum, only the lanes using the $U$. marinum gene as a template showed a single clear band. The result of sequence comparison showed that the amplified sequence of the specific primer was consistent with the target sequence.

\section{Discussion}

In the present study, by performing a comparative analysis of the mitochondrial genomes of P. persalinus and $U$. marinum, which are very similar in morphological forms, the nad4 and nad7 genes were first proposed as molecular markers to differentiate these ciliate species. The interaction between nicotinamide adenine dinucleotide (NAD+) and NAD+--dependent enzyme plays an important role in cellular redox reactions, energy metabolism, and signal transduction processes. NADH dehydrogenase subunit genes include nad1, nad4, nad2, nad5 [28], $n a d 7$, and so on. Several studies have reported the application of NADH dehydrogenase subunit genes in species identification and genetic variation as interspecific 


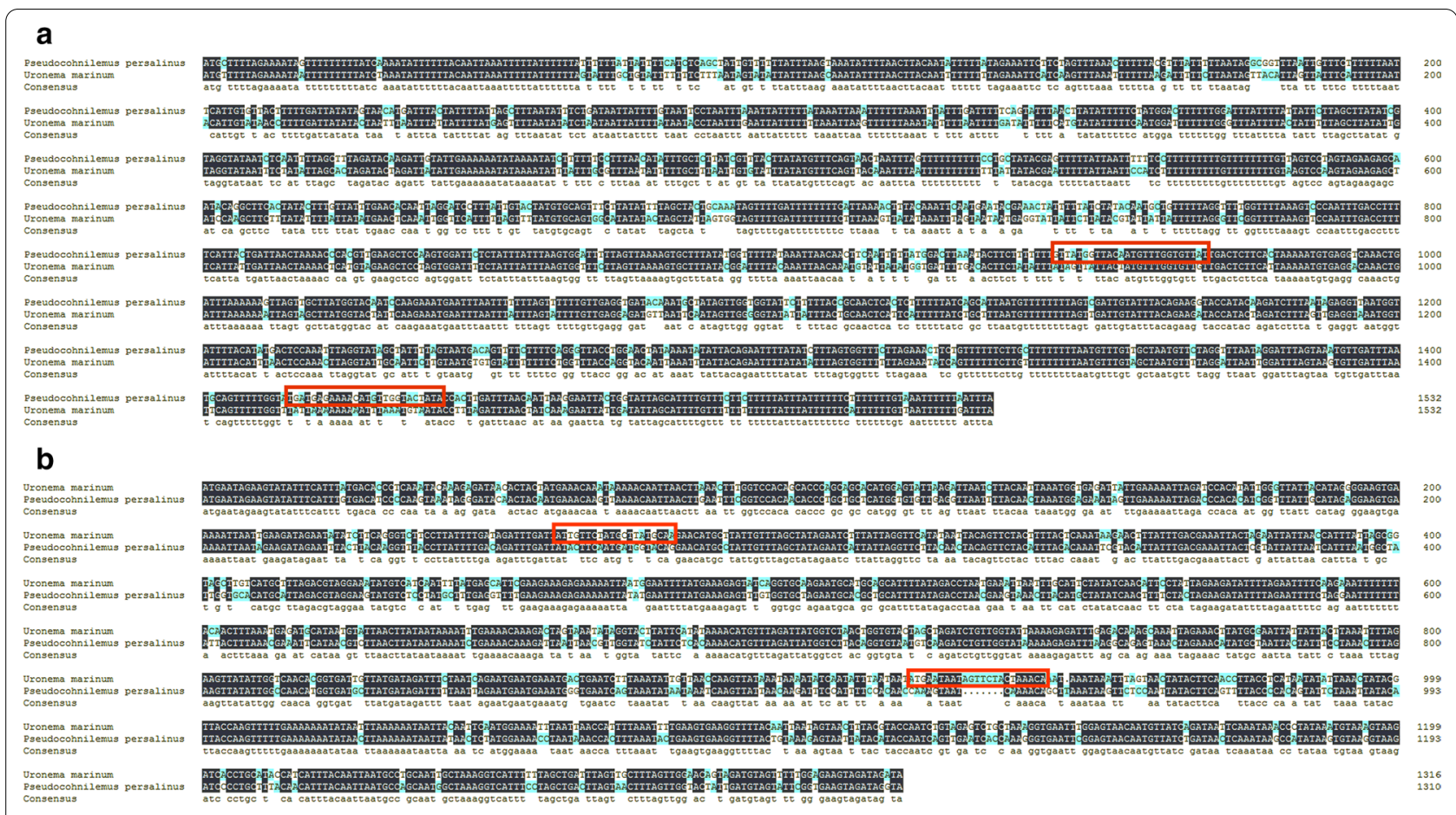

Fig. 7 Comparison of selected gene sequences and design of primers. a Comparison of the nad4 gene between P. persalinus and U. marinum. The first line is $P$. persalinus and the second one is $U$. marinum. $\mathbf{b}$ Comparison of the nad7 gene between P. persalinus and U. marinum. The first line is $U$. marinum and the second one is $P$. persalinus. The two primers are indicated by red boxes

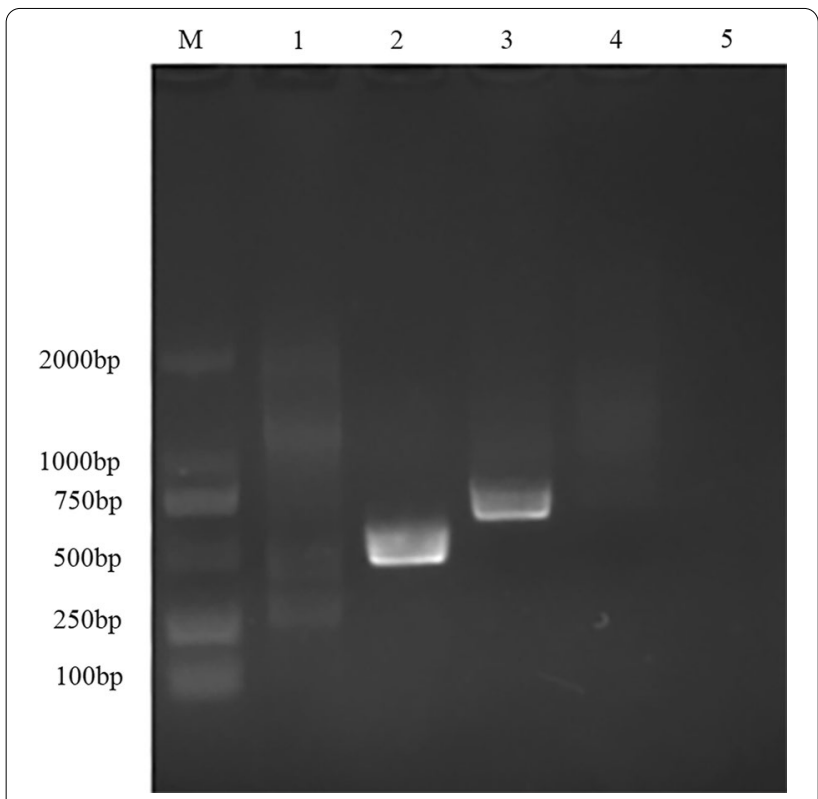

Fig. 8 Result of specific primer amplification. M: Marker; Lane 1: The DNA template was U. marinum and the primer was P2; Lane 2: DNA template was P. persalinus and the primer was P2; Lane 3: DNA template was U. marinum and the primer was P3; Lane 4: DNA template was P. persalinus and the primer was P2; Lane 5: Blank control genetic markers. The nad1 (NADH dehydrogenase subunit 1) gene has a higher nucleotide replacement rate and greater variability than other mitochondrial genes [29]. Choudhary et al. deduced the genetic structure and diversity of Bactrocera zonata based on the nad1 gene and $\operatorname{cox} 1$ (mitochondrial cytochrome c oxidase subunit 1) gene [30]. Mikaeili et al. used the $\operatorname{nad} 1$ and $\operatorname{cox} 1$ genes to identify Toxocara canis and Toxocara cati [31]. The nad4 (NADH dehydrogenase subunit 4) gene is one of the genes that evolved faster in the mitochondria. In the field of the classification, identification, and population inheritance of parasites, many scholars believe that the nad4 gene sequence is an ideal genetic marker. For example, $\mathrm{Li}$ et al. used nad4 to find interspecies differences among $T$. canis, T. cati, Toxocara malaysiensis, Toxocara vitulorum, and Toxascaris leonina from different regions [32]. Hao et al. found that the genetic variation of the $\operatorname{cox} 1$ gene in Ascaridia galli was lower than that of the nad4 gene, and they therefore considered that the nad4 gene was more suitable than the $\operatorname{cox} 1$ gene as a molecular marker for studying the genetic variation of $A$. galli [33]. The nad7 gene was also considered to be an accurate fragment for species identification and phylogenetic reconstruction; it was used for identifying Amoebozoa [34] and was also reported to be used for identifying Russian wild ginseng and Mielichhoferia elongata [35, 36]. The experimental 
results of the present study also proved that the nad4 and nad7 genes were ideal genetic markers for studying the identification of ciliate species.

The morphological forms of scuticociliates are too similar to be identified and distinguished visually. In recent years, because of the improvements in methods for obtaining molecular information of ciliates and the wide application of bioinformatics analytical methods, genetic analysis of ciliates has become a common method to study the phylogenetic evolution of ciliates. However, most gene analyses of ciliates were limited to basic gene sequencing, and the subsequent analysis was mostly limited to the analysis and comparison of SSU-rDNA and $18 \mathrm{~S}$ rRNA. For example, Stidworthy et al. used SSUrDNA to analyze and identify Philasterides dicentrarchi, which lives in sharks [37], and Felipe et al. identified $P$. dicentrarchi and $M$. avidus as different species using $18 \mathrm{~S}$ rRNA, $\alpha$-tubulin, and $\beta$-tubulin genes [38]. However, these methods cannot fully meet the requirements of ciliate classification and function research; therefore, reports on using different methods to analyze ciliate genes have gradually increased. $P$. persalinus was identified using a fluorescent dye-labeled SSU-rDNA-targeted oligonucleotide probe, which was optimized in fluorescence in situ hybridization (FISH) by Zhan et al. [39]. Xiong et al. sequenced the whole genome of $P$. persalinus and analyzed horizontal gene transfer (HGT) to understand its virulence [40]. Whang et al. found that the genetic differences in the $\operatorname{cox} 1$ sequence were greater than those of SSU-rDNA in $P$. persalinus, $P$. longisetus, $U$. marinum, and $M$. avidus. The authors designed specific primers based on the cox 1 sequence to successfully identify them [13]. In the present study, specific primers were designed based on the nad4 gene and the nad7 gene of P. persali$n u s$ and $U$. marinum. These primers could serve as a fast and accurate tool for species identification of scuticociliates. The function and composition of the mitochondrial genomes of $P$. persalinus and $U$. marinum were also analyzed in detail to provide a solid data foundation for follow-up research.

\section{Conclusions}

In conclusion, the whole mitochondrial genomes of $P$. persalinus and $U$. marinum were thoroughly compared by analyzing nucleotide composition, codon usage, Ka/ $\mathrm{Ks}$, and p-distance. In addition, we compared amino acid and nucleotide identity of $P$. persalinus and $U$. marinum with 12 other related ciliates and constructed a phylogenetic tree. We have successfully designed specific PCR primers to identify $P$. persalinus and $U$. marinum using the nad4 and nad7 genes.
Abbreviations

PCR: Polymerase chain reaction; NCBI: National Center for Biotechnology Information; ORF: Open reading frame; RSCU: Relative synonymous codon usage; COGs: Clusters of Orthologous Groups; Ka: Number of non-synonymous substitutions per non-synonymous site; Ks: Number of synonymous substitutions per synonymous site.

\section{Supplementary Information}

The online version contains supplementary material available at https://doi. org/10.1186/s13071-021-04821-3.

Additional file 1: Table S1. Ka/Ks values of 25 common encoding genes of P. persalinus and U. marinum.

\section{Acknowledgements}

We thank the scientists and personnel of Guangzhou Science Corporation of Gene and Dalian Ocean University for their support and collaboration.

\section{Authors' contributions}

YXH performed the data analysis and wrote the manuscript. SW, YQG, and $J H C$ performed the research. XLW performed the data analysis. RJL designed the research and supported this work. All authors read and approved the final manuscript.

\section{Funding}

This work was funded in part by the Nature Science Foundation Guidance Program of Liaoning Science and Technology Department (2019-ZD-0733), High-Level Talents Innovation Support Program of Dalian (2019RQ111), China Agriculture Research System of MOF and MARA (CARS-47), and Basic Scientific Research Project for Colleges and Universities of Education Department in Liaoning Province.

\section{Availability of data and materials}

The whole mitochondrial genome sequences of $P$. persalinus and U. marinum are deposited at NCBI (https://www.ncbi.nlm.nih.gov/), with the following accession numbers: MH608212 and MG272262. The other data supporting our findings and conclusions are available in the article.

\section{Declarations}

Ethics approval and consent to participate Not applicable.

\section{Consent for publication}

Not applicable.

\section{Competing interests}

The authors declare that they have no competing interests.

\section{Author details}

${ }^{1}$ Liaoning Key Laboratory of Marine Animal Immunology, Dalian Key Laboratory of Marine Animal Disease Control and Prevention, College of Fisheries and Life Science, Dalian Ocean University, Dalian, Liaoning 116023, People's Republic of China. ${ }^{2}$ Science Corporation of Gene, Guangzhou, Guangzhou 510000, People's Republic of China.

Received: 3 January 2021 Accepted: 2 June 2021

Published online: 10 June 2021

\section{References}

1. Dyková I, Tyml T, Kostka M, Pecková H. Strains of Uronema marinum (Scuticociliatia) co-isolated with amoebae of the genus Neoparamoeba. Dis Aquat Org. 2010;89:71-7.

2. Piazzon MC, Leiro J, Lamas J. Fish immunity to scuticociliate parasites. Dev Comp Immunol. 2013;41:248-56. 
3. Smith PJ, McVeagh SM, Hulston D, Anderson SA, Gublin Y. DNA identification of ciliates associated with disease outbreaks in a New Zealand marine fish hatchery. Dis Aquat Org. 2009:86:163-7.

4. Munday BL, O'Donoghue PJ, Watts M, Rough K, Hawkesford T. Fatal encephalitis due to the scuticociliate Uronema nigricans in sea-caged, southern bluefin tuna Thunnus maccoyii. Dis Aquat Org. 1997;30:17-25.

5. Pan X, Zhu M, Ma H, Al-Rasheid KAS, Hu X. Morphology and small-subunit rRNA gene sequences of two novel marine ciliates, Metanophrys orientalis spec. Nov. and Uronemella sinensis spec. Nov. (Protista, Ciliophora, Scuticociliatia), with an improved diagnosis of the genus Uronemella. Int J Syst Evol Microbiol. 2013;63:3515-23.

6. Alvarez-Pellitero P, Palenzuela O, Padros F, Sitja-Bobadilla A, Riaza A, Silva $\mathrm{R}$, et al. Histophagous scuticociliatids (Ciliophora) parasitizing turbot Scophthalmus maximus: morphology, in vitro culture and virulence. Folia Parasitol. 2004;51:177-87.

7. Song JY, Kitamura SI, Oh MJ, Kang HS, Lee JH, Tanaka SJ, et al. Pathogenicity of Miamiensis avidus (syn. Philasterides dicentrarchi), Pseudocohnilembus persalinus, Pseudocohnilembus hargisi and Uronema marinum (Ciliophora, Scuticociliatida). Dis Aquat Org. 2009;83:133-43.

8. Jung SJ, Kitamura SI, Song JY, Oh MJ. Miamiensis avidus (Ciliophora: Scuticociliatida) causes systemic infection of olive flounder Paralichthys olivaceus and is a senior synonym of Philasterides dicentrarchi. Dis Aquat Org. 2007;73:227-34.

9. Kim SM, Cho JB, Lee EH, Kwon SR, Kim SK, Nam YK, et al. Pseudocohnilembus persalinus (Ciliophora: Scuticociliatida) is an additional species causing scuticociliatosis in olive flounder Paralichthys olivaceus. Dis Aquat Org. 2004:62:239-44

10. Jung SJ, Kitamura SI, Song JY, Jeong IY, Oh MJ. Complete small subunit rRNA gene sequence of the scuticociliate Miamiensis avidus pathogenic to olive flounder Paralichthys olivaceus. Dis Aquat Org. 2005;64:159-62.

11. Puig L, Traveset R, Palenzuela O, Padros F. Histopathology of experimental scuticociliatosis in turbot Scophthalmus maximus. Dis Aquat Org. 2007:76:131-40.

12. Dragesco A, Dragesco J, Coste F, Gasc C, Romestand B, Raymond J, et al. Philasterides dicentrarchi n. sp. (ciliophora, Scuticociliatida), a histophagous opportunistic parasite of Dicentrachus labrax (Linnaeus, 1758), a reared marine fish. Eur J Protistol. 1995;31:327-40.

13. Whang I, Kang H-S, Lee J. Identification of scuticociliates (Pseudocohnilembus persalinus, P. longisetus, Uronema marinum and Miamiensis avidus) based on the cox1 sequence. Parasitol Int. 2013;62:7-13.

14. Jung SJ, Im EY, Strüder-Kypke MC, Kitamura SI, Woo PTK. Small subunit ribosomal RNA and mitochondrial cytochrome c oxidase subunit 1 gene sequences of 21 strains of the parasitic scuticociliate Miamiensis avidus (Ciliophora, Scuticociliatia). Parasitol Res. 2011;108:1153-61.

15. Gao YQ, Jin SB, Dang HF, Ye SG, Li RJ. Mitochondrial genome sequencing of notorious scuticociliates (Pseudocohnilembus persalinus) isolated from Turbot (Scophthalmus maximus L.). Mitochondrial DNA, Part B. 2018;3:1077-8.

16. Li RJ, Gao YQ, Hou YL, Ye SG, Wang LS, Sun JX, et al. Mitochondrial genome sequencing and analysis of scuticociliates (Uronema marinum) isolated from Takifugu rubripes. Mitochondrial DNA, Part B. 2018;3:736-7.

17. Song WB, Zhu MZ, Chen ZG, Wang M. Diagnostic assessment of some common pathogenic genera within the order Scuticociliatida: members inhabiting mariculture biotopes. Period Ocean Univ China. 2000:2:207-16

18. Bernt M, Donath A, Jühling F, Externbrink F, Florentz C, Fritzsch G, et al. MITOS: improved de novo metazoan mitochondrial genome annotation. Mol Phylogenet Evol. 2013;69:313-9.

19. Sharp PM, Li WH. The codon Adaptation Index-a measure of directional synonymous codon usage bias, and its potential applications. Nucleic Acids Res. 1987;15:1281-95.

20. Edgar RC. MUSCLE: multiple sequence alignment with high accuracy and high throughput. Nucleic Acids Res. 2004;32:1792-7.

21. Wang DP, Zhang YB, Zhang Z, Zhu J, Yu J. KaKs_Calculator 2.0: a toolkit incorporating gamma-series methods and sliding window strategies. Genomics, Proteomics Bioinf. 2010:8:77-80.

22. Tamura K, Stecher G, Peterson D, Filipski A, Kumar S. MEGA6: molecular evolutionary genetics analysis version 6.0. Mol Biol Evol. 2013;30:2725-9.
23. Posada D. jModelTest: phylogenetic model averaging. Mol Biol Evol. 2008:25:1253-6.

24. Ronquist F, Teslenko M, Mark P, Ayres DL, Darling A, Höhna S, et al. MRBAYES 3.2: efficient Bayesian phylogenetic inference and model selection across a large model space. Syst Biol. 2012;61:539-42.

25. Stamatakis A. RAxML-VI-HPC: maximum likelihood-based phylogenetic analyses with thousands of taxa and mixed models. Bioinformatics. 2006;22:2688-90

26. Grant JR, Arantes AS, Stothard P. Comparing thousands of circular genomes using the CGView comparison tool. BMC Genomics. 2012;13:202.

27. Guy L, Kultima JR, Andersson SGE. genoPlotR: comparative gene and genome visualization in R. Bioinformatics. 2010;26:2334-5.

28. Laurimäe T, Kinkar L, Romig T, Umhang G, Casulli A, Omer RA, et al. Analysis of nad 2 and nad5 enables reliable identification of genotypes $G 6$ and $\mathrm{G} 7$ within the species complex Echinococcus granulosus sensu lato. Infect Genet Evol. 2019;74:103941

29. Wan X, Nardi F, Zhang B, Liu Y. The oriental fruit fly, Bactrocera dorsalis, in China: origin and gradual inland range expansion associated with population growth. PLoS One. 2011;6:e25238.

30. Choudhary JS, Naaz N, Lemtur M, Das B, Singh AK, Bhatt BP, et al. Genetic analysis of Bactrocera zonata (Diptera: Tephritidae) populations from India based on cox 1 and nad 1 gene sequences. Mitochondrial DNA Mapp Seq Anal. 2018;29:727-36.

31. Mikaeili F, Mathis A, Deplazes P, Mirhendi H, Barazesh A, Ebrahimi S, et al. Differentiation of Toxocara canis and Toxocara cati based on PCR-RFLP analyses of rDNA-ITS and mitochondrial cox 1 and nad 1 regions. Acta Parasitol. 2017;62:549-56.

32. Li MW, Lin RQ, Song $H Q$, Sani RA, Wu XY, Zhu XQ. Electrophoretic analysis of sequence variability in three mitochondrial DNA regions for ascaridoid parasites of human and animal health significance. Electrophoresis. 2008;29:2912-7.

33. Hao GY, He XQ, Wan R. Genetic variation analysis of mitochondrial cox 1 and nad 4 genes of Ascaridia galli. China Anim Husb Vet Med. 2017:44:113-22.

34. Blandenier Q, Lara E, Mitchell EAD, Alcantara DMC, Siemensma FJ, Todorov M, et al. NAD9/NAD7 (mitochondrial nicotinamide adenine dinucleotide dehydrogenase gene)—a new "Holy Grail" phylogenetic and DNA-barcoding marker for Arcellinida (Amoebozoa)? Eur J Protistol. 2017:58:175-86.

35. Li GS, Yan C, Wang HT, Kwon WS, Yang DC. Molecular differentiation of Russian wild ginseng using mitochondrial nad7 intron 3 region. J Ginseng Res. 2016;41:326-9.

36. Goruynov DV, Goryunova SV, Kuznetsova OI, Logacheva MD, Milyutina IA, Fedorova AV, et al. Complete mitochondrial genome sequence of the "copper moss" Mielichhoferia elongata reveals independent nad7 gene functionality loss. PeerJ. 2018;6:e4350.

37. Stidworthy MF, Garner MM, Bradway DS, Westfall BD, Joseph B, Repetto $\mathrm{S}$, et al. Systemic Scuticociliatosis (Philasterides dicentrarchi) in sharks. Vet Pathol. 2014;51:628-32.

38. De Felipe A-P, Lamas J, Sueiro R-A, Folqueira I, Leiro J-M. New data on flatfish scuticociliatosis reveal that Miamiensis avidus and Philasterides dicentrarchi are different species. Parasitology. 2017:144:1394-411.

39. Zhan ZF, Stoeck T, Dunthorn M, Xu KD. Identification of the pathogenic ciliate Pseudocohnilembus persalinus (Oligohymenophorea: Scuticociliatia) by fluorescence in situ hybridization. Eur J Protistol. 2014;50:16-24.

40. Xiong J, Wang GY, Cheng J, Tian M, Pan XM, Alan W, et al. Genome of the facultative scuticociliatosis pathogen Pseudocohnilembus persalinus provides insight into its virulence through horizontal gene transfer. Sci Rep. 2015;5:15470.

\section{Publisher's Note}

Springer Nature remains neutral with regard to jurisdictional claims in published maps and institutional affiliations. 